\title{
Swine ultrasonography numerical modeling for pregnancy diagnosis and prediction of litter size
}

\author{
Konstantinos Kousenidis ${ }^{1}$, Ioannis A. Giantsis ${ }^{2}$, Efstathia Karageorgiou ${ }^{1}$ and Melpomeni Avdi ${ }^{3}$ \\ ${ }^{1}$ Department of Animal Production, International Hellenic University, Sindos Thessaloniki, Greece. \\ ${ }^{2}$ Department of Animal Science, Faculty of Agricultural Sciences, University of Western Macedonia, \\ Greece. \\ ${ }^{3}$ Department of Animal Production, Faculty of Agriculture, Aristotle University of Thessaloniki, \\ Greece.
}

Received: July 24, 2020. Revised: January 20, 2021. Accepted: February 10, 2021. Published: February 12, 2021.

\begin{abstract}
Early and reliable diagnosis of pregnancy in sows is considered one of the most crucial parameters for the proper management in pig farming. Reproductive activity of the sows is directly correlated with the overall productivity of the enterprise. The best and most precise methodology to diagnose pregnancy in farm animals, including pigs, is ultrasonography. For getting optimal outputs of real-time ultrasonography application in pigs, both gestation status and litter size of sows is of high importance. Hence, a detailed evaluation and careful reading of the retrieved ultrasonic image could serve to the prediction of the sow's litter size, providing valuable information to the producer. In the present article we studied the ultrasonic typification of sows in an effort to develop a methodology for the precise pregnancy diagnosis and the prediction of the litter size. To achieve this goal, 1214 matings and 1010 pregnancies were recorded and evaluated over a period of 20 months, in a pig unit in Northern Greece. Two thorough scans were performed on each sow, classifying the ultrasonic image in a scale of 0 to 10,0 being 'non pregnant' and 10 given to the most reassuring image of pregnancy. Evaluations took place in a wide range of time since mating, hence between days 16 (the earliest first scan) and 68 (the latest that a second scan was performed) and the mean values obtained were 8,36 and 8,83 for the first and second scan respectively. Furthermore, the litter size of each subsequent parturition was recorded (mean: 12.22) and correlated to the score of each of the two scans performed during pregnancy. The results showed that more reassuring images and higher scores for both examinations of pregnancy were achieved
\end{abstract}

with increasing time interval from mating $(P<0.05)$. It is therefore suggested that a detailed real-time ultrasonic scanning, can provide a very useful tool, not only for pregnancy diagnosis, but also for the prediction of litter size and eventually the precise management of pregnant sows.

Keywords-embryo development, pregnancy diagnosis, sow, ultrasonic.

\section{INTRODUCTION}

Facing a massively increasing demand in both industrialized world and developing countries, livestock production is characterized as the next food revolution that also addresses a huge global market competition [1]. On account of the high competition, producers are under pressure for reducing the price of their products and in the same time have to address consumer's awareness for animal welfare and production of more eco-friendly products. Among the livestock animals, more than any other meat consumed in the world is owed to the pork industry, in which the sow gestation is considered the most visible animal welfare issue in commercial pig farming [2].

Sow productivity has changed dramatically during the recent decades. The biological limit for most modern sows is between 13-14 piglets [3]. Continuous genetic selection has led to high fertility of sows and the production of lean offspring. As a result, modern sows produce larger calving groups and each offspring is leaner and grows faster [4]. The reproductive process is the key element of breeding and must be properly managed. The reproductive function of a sow is divided into the following stages: estrus, mating, pregnancy, piglet birth, lactation, weaning, followed by a short interval 
until the manifestation of the next estrus.

Apart from the concerns raised, related to the impact of housing of pregnant sows in pig industry [5,6], it should be also noted that keeping breeding sows is a process of increased costs that is reflected in the final product. In this context, early and precise diagnosis of pregnancy in sows is crucial for the cost effective management of a pig farm [7], in an effort to avoid unnecessary treatment of erroneous characterized animals as pregnant.

Ultrasonography is the best and most precise methodology to diagnose pregnancy at the earliest possible stage in both pigs of industrialized farms and outdoor reared ones [8,9]. On account of the high importance of the stage that pregnancy is diagnosed for the proper management of a pig farm, early diagnosis is considered the main advantage of the method [7]. However the costs related with the operation constitute the basic drawback of the method that cannot be ignored [10]. Thus, despite the continuous market price drops, the efficiency of the process is essential.

During pregnancy, the efficiency of the method is getting substantially improved as days are passing [11]. In general, the utilization of the ultrasound methodology within the first 2-3 weeks of the pregnancy is not feasible [12]. Pregnancy can be first diagnosed in swine approximately 18-24 days after natural mating or artificial insemination and needs to be confirmed by a second examination 35-40 days post-mating $[13,14]$. This need for confirmation is on account of to the high mortality rate observed up to the 30th day of gestation [15]. After the 23rd - 24th day post-mating, the real time ultrasound (RTU) is considered to give the most accurate results for pregnancy diagnosis in farmed sows [6,9].

Establishment of the RTU methodology for pregnancy diagnosis in pig farms resulted in two major improvements; the better monitoring of swine females returning to estrus and the reduction of the non-productive periods [16]. Hence, the main management advantage is the rapid rebreeding or removal of early-identified non-pregnant animals [14]. However, keeping in mind the RTU costs in combination with the potential diagnosis failure, it is very important to achieve the highest possible accuracy and efficiency when conducting the operation. Although the best approximate post-mating time period for the operation is already known, there is a lack of information regarding the precise day for the most successful diagnosis.

This study was designed to examine the RTU images of pregnant sows aiming to assess the best-proposed post-mating day for the operation. Furthermore, our scope was to evaluate and develop a rating scale whereby using the RTU image would diagnose pregnancy and predict the litter size in pregnant sows.

\section{MATERIALS AND METHODS}

\section{A. Animals, farming conditions and ultrasonic operations}

All RTU scans were performed in a farm with capacity for 300 sows, located in northern Greece. Animal manipulations were in accordance with the EU Directive on the protection of animals' usage for scientific purposes (2010/63/EU). During the performance of the trials, the mean number of sows ranged between 260 and 280. The animals of the farm constitute a crossbred population between Large White and Landrace. In particular, approximately half of the examined animals were the F1-crossbred between pure Large White and pure Landrace (F1), whereas the other half were crossbred between the F1 females and pure Large White males. The F1 sows were initially purchased from breeding companies. These animals constituted the main breeding stock, which was enriched by females produced within the farm.

Housing of the sows took place either in individual crates or in groups of seven animals. Two different feedstuffs were offered to the sows, one during lactation and the other one during the dry period. Fertilizations were all performed by artificial insemination using semen material collected with sterilized cups from males that mounted on dummy sows in separate pens. The collected semen was diluted and preserved in the sperm laboratory of the farm before fertilization. After manifestations of estrous, which were detected in swine females applying boar exposure, inseminations were carried out on estrous sows in two doses of $100 \mathrm{~mL}\left(>3 \times 10^{9}\right.$ spermatozoa per dose), with a time interval of 18-24 hours. The procedure was repeated in weaned sows, housed in individual crates, where they stayed up to estrous manifestation, fertilization and pregnancy confirmation using ultrasonography.

For pregnancy diagnosis, a real time ultrasound scanner (Agroscan A7, Echo Control Medical, France) provided with a $5 \mathrm{MHz}$ linear transducer was utilized. For the operation of the diagnosis, the transducer was held against the hind abdomen, forming a $45^{\circ}$ angle at the height of the second nipple line. Mineral coupling gel was also utilized for the effective transmission of the ultrasound waves, as suggested by Knox and Althouse [13].

\section{B. Reproductive data collection}

Data were collected from 415 sows in a two-year period between September 2014 and September 2016. The gilts and sows were not hormonally treated for synchronization of estrous and born piglets were removed from the sows at the time of weaning, approximately after 28 days of lactation. Estimations in diagnosis of pregnancy were based on the displayed dark dots that corresponded to the gestational sacs within the uterine tissue. Apart from pregnancy diagnosis, estimations concerned the evaluation of the similarity of the ultrasonography image with the image of a confirmed pregnancy. Based on the degree of similarity and on the approximate number of cystic follicles, a 10-point rating scale was established, with value " 0 " corresponding to complete absence of pregnancy indications and value "10" given when the screen is completely covered by the embryonic vesicles (Figure 1).

Two scans for pregnancy diagnosis were performed in each animal, the first of which between days 16 and 53 after 
insemination and the second between days 28 and 68 after insemination and hence two rating scale scores were given in each animal. The collected data included the ear tag of each sow, the insemination date, the first and the second given scale score, the date of the first and the second scan, the date of birth and the number of born piglets. Based on these data we estimated (a) the time of the first scan in days, (b) the time of the second scan in days, (c) the fecundity of the experimental population and (d) the percentage of births.

\section{Statistical analysis}

We initially examined the effect of the scale score derived from the two pregnancy diagnosis scans as well as the effect of the operation time (measured in days) on the total number of born piglets. The association of the total number of born piglets with the scale scores was investigated using a generalized linear model. Additionally, a $\chi^{2}$ and a $t$-test were carried out to determine the effect of the scale score on the number of piglets born. Furthermore, a multiple regression analysis was performed for the establishment of a prediction model for the litter size using real time ultrasonography in two gestational stages of the sow. All analyses were performed using the statistical package IBM SPSS version 23.

\section{RESUlts}

In total, 1214 fertilizations and 1010 births were reported during the periods September 2014 - June 2016 and January 2015 - September 2016, respectively. The mean number of born piglets was $12.22 \pm 3.19$. Out of the 204 remaining sows that failed in reproduction, a return to estrus was observed in 166 and a pregnancy loss (abortion) was observed in 38 animals. Thus, the fertilization rate was $86.18 \%$ whereas the birth rate was $83.2 \%$. The mean rating scale values (RSV) according to the 10-point rating scale (Figure 1) given to the tested sows are presented in Table 1. The mean RSV were high for both scans in sows that successfully gave birth, lower in sows that were pregnant and aborted and very low for sows that returned to estrus (Table 1).

Table 1. Given rating scale scores to tested sows according to Figure 1. RSV, rating scale value; N, number of tested sows; S.D., standard deviation.

\begin{tabular}{lll}
\hline Sows & Mean $1^{\text {st }}$ RSV & Mean $2^{\text {nd }}$ RSV \\
\hline $\begin{array}{l}\text { Sows that gave birth } \\
(\mathrm{N}=1010)\end{array}$ & $8.36($ S.D. $=1.58)$ & $8.83($ S.D. $=1.09)$ \\
$\begin{array}{l}\text { Sows that aborted } \\
(\mathrm{N}=38)\end{array}$ & $7.20($ S.D. $=3.10)$ & $6.17($ S.D. $=4.09)$ \\
$\begin{array}{l}\text { Returned to estrus } \\
\text { sows }(\mathrm{N}=166)\end{array}$ & $4.03($ S.D. $=1.99)$ & $4.67($ S.D. $=2.99)$ \\
\hline
\end{tabular}

Variability of the RSV was greater before the day 23 and was reduced between days 25 and 35 post insemination, whereas they were in consistently high levels when the first scan was conducted after day 35 post insemination (Figure 2). Regarding the second scan, the variability of the RSV was generally lower and irrespective of the earliness of the operation, with the majority of the given scores greater than 8 (Figure 2).
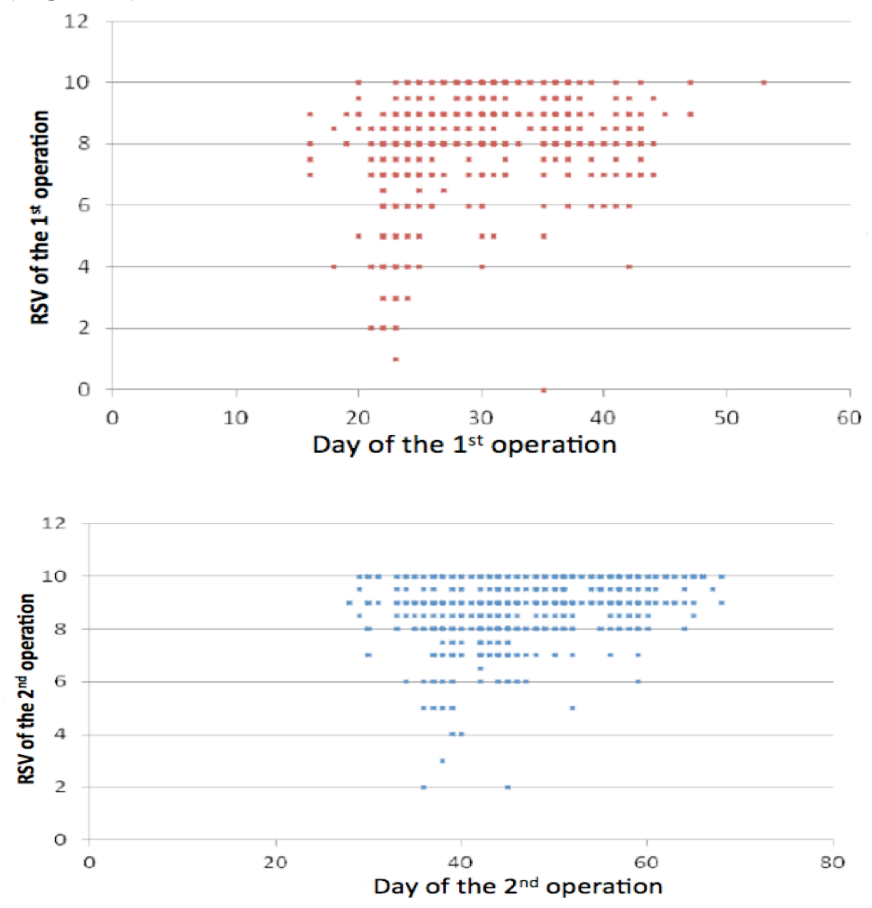

Figure 2. RSV of the first and the second scan in relation with the day of the operation

The RSV given in the first scan presented stabilization in a high level after the day 26, when the time of the first scan was clustered in 5-day groups, concerning only animals that successfully gave birth to piglets (Table 2).

Table 2. Mean RSV of the 1 st and 2nd scan according to 5-day groups of the first ultrasonography

\begin{tabular}{|c|c|c|c|c|}
\hline $\begin{array}{l}\text { 5-day } \\
\text { group }\end{array}$ & $\begin{array}{c}\text { Mean } \\
\text { RSV } \\
\left(1^{\text {st }} \text { scan }\right)\end{array}$ & $\begin{array}{c}\text { Min-Max } \\
\text { RSV of } \\
\text { the } 1^{\text {st }} \\
\text { scan }\end{array}$ & $\begin{array}{l}\text { Number of } \\
\text { operations }\end{array}$ & $\begin{array}{l}\text { Mean } \\
\text { RSV of } \\
\text { the } 2^{\text {nd }} \\
\text { scan } \\
\text { (days) }\end{array}$ \\
\hline $16-20$ & 8.34 & 4-10 & 22 & $\begin{array}{c}8.52 \\
(33-40)\end{array}$ \\
\hline $21-25$ & 7.17 & $1-10$ & 300 & $\begin{array}{r}8.60 \\
(28-61)\end{array}$ \\
\hline $26-30$ & 8.96 & 4-10 & 275 & $\begin{array}{r}8.70 \\
(34-66)\end{array}$ \\
\hline $31-35$ & 9.13 & $5-10$ & 187 & $\begin{array}{c}8.97 \\
(38-68)\end{array}$ \\
\hline $36-40$ & 8.89 & $6-10$ & 158 & $\begin{array}{c}9.17 \\
(43-65)\end{array}$ \\
\hline $41-45$ & 8.10 & 4-10 & 54 & $\begin{array}{r}9.00 \\
(48-64)\end{array}$ \\
\hline $46-53 *$ & 9.38 & $9-10$ & 8 & $\begin{array}{r}9.69 \\
(65-66) \\
\end{array}$ \\
\hline
\end{tabular}

*The last group was extended to 8 days due to the small number of operations 
Furthermore, although estimations of the first 5-day group were high, the mean RSV were reduced in the second 5-day group that is of high zootechnical importance. All mean estimations of the second ultrasonography scan were high for this grouping. The day of the first scan was statistically significantly correlated with the first ultrasonography RSV estimations $(\mathrm{P}<0.001)$. When days were clustered in 5 -day groups based on the time of the second scan, the mean RSV were always high ranging between 8.31 and 9.60 (Table 3). In accordance to Table 2, the mean RSV of the first scan for the first two 5-day groups were the lowest. Similarly to the previous grouping, the day of the second scan and the second scan RSV presented a significant correlation $(\mathrm{P}<0.001)$.

Descriptive statistics indicted that when clear evidence for pregnancy is provided (RSV $>6$, Figure 1), the mean time of the first scan was within the duration of 25-31 days (Table 4). On the other hand, sows with scores lower than 6 had always a litter size of 7-10 fetuses, whereas sows with scores 9 or 10 had litter sizes of 12 or 13 . In these cases the second score was always higher. Regarding the second scan, low RSV were observed only in a limited sample (Table 4), whereas the mean time in days for all categories was high. Furthermore, based on this categorization, RSV of the first scan were significantly correlated with the RSV of the second scan $(\mathrm{P}<0.001)$.

The effect of the RSV on the number of piglets born, based on the multiple regression analysis, was statistically significant $\left(\mathrm{R}^{2}=0.108, \mathrm{P}<0.0001 ; \chi^{2}=10.884, \mathrm{df}=2, \mathrm{p}=0.003\right.$; $\mathrm{P}<0.001$, Student's $t$-test). However, the day of the operation as a covariance factor did not present a significant effect on the number of born piglets. The effect of the RSV on the number of piglets born was increased when the impact of the sow was also included in the model $\left(\mathrm{R}^{2}=0.595, \mathrm{P}=0.011\right)$. Eventually, a prediction model was designed for the number of piglets to be born:

$$
\mathrm{Y}=14,052-0,075 \times \mathrm{V}_{1} \times \mathrm{D}_{1}-0,022 \times \mathrm{V}_{2} \times \mathrm{D}_{2}
$$

where $\mathrm{Y}$ is the number of born piglets, $\mathrm{V}_{1}$ the RSV of the first scan, $D_{1}$ the day of the first scan, $V_{2}$ the RSV of the second scan and $\mathrm{D}_{2}$ the day of the second scan.
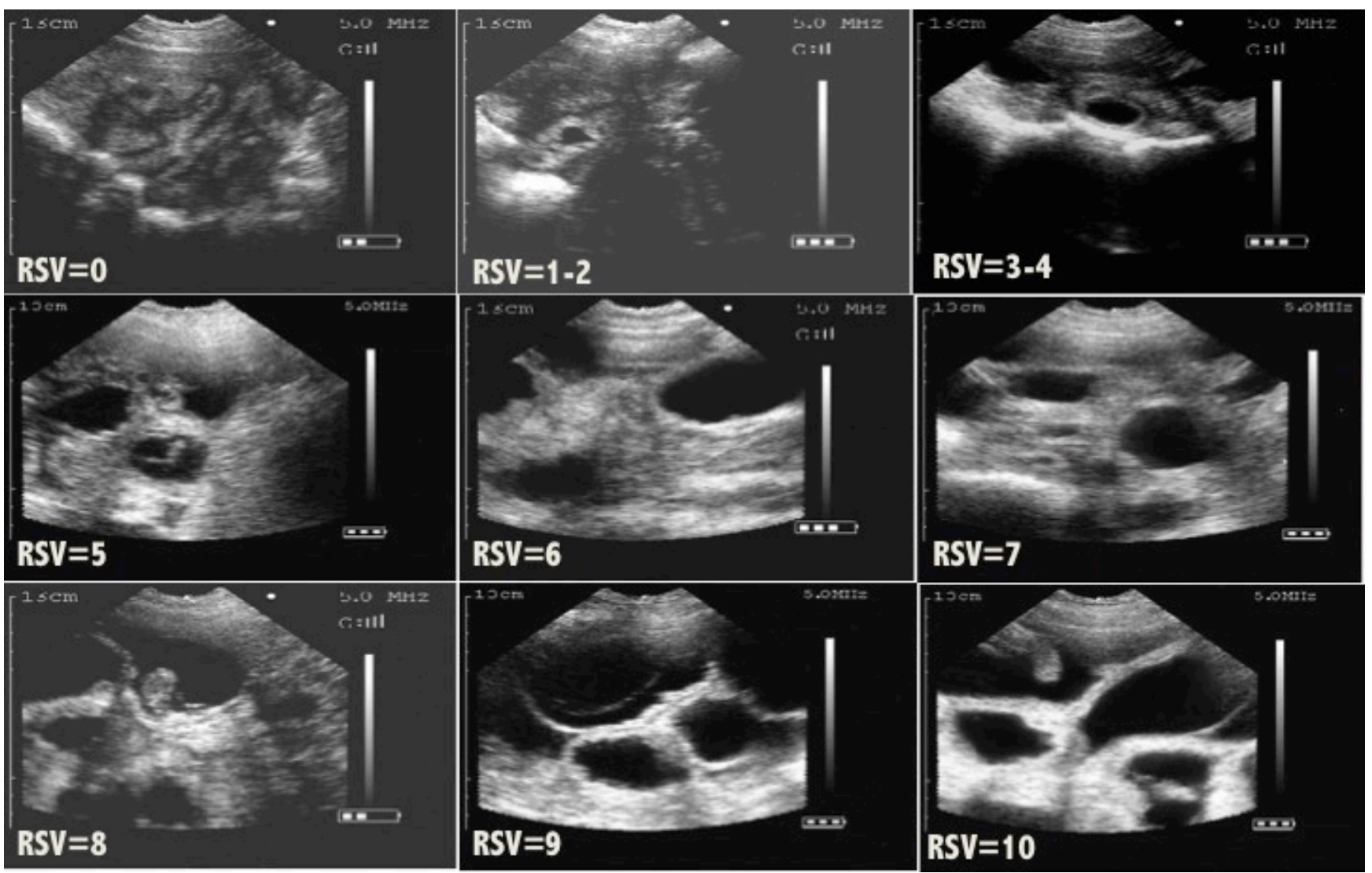

Figure 1. The 10-point rating scale for the pregnancy diagnosis estimation. $\mathrm{RSV}=0$ : complete absence of pregnancy indications, RSV=1-2: low suspicion for pregnancy - typical image within 20 days post insemination, RSV=3-4: reasonable suspicion for pregnancy - typical image within 20-24 days post insemination, $\mathrm{RSV}=5$ : guaranteed pregnancy with possible small litter size, RSV=6: guaranteed pregnancy of medium litter size - typical image within 25-30 days post insemination, $\mathrm{RSV}=7$ : guaranteed pregnancy with possible larger litter size, $\mathrm{RSV}=8$ : guaranteed pregnancy of satisfactory litter size, RSV=9: guaranteed pregnancy of possibly great litter size - typical image at least 25 days post insemination, $\mathrm{RSV}=10$ : great litter size. 
Table 3. Mean RSV of the 1st and 2nd scan according to 5-day groups of the second ultrasonography

\begin{tabular}{lllll}
\hline 5-day & $\begin{array}{l}\text { Mean } \\
\text { RSV of } \\
\text { the } \\
1^{\text {st }} \text { scan } \\
\text { (days) }\end{array}$ & $\begin{array}{l}\text { Mean } \\
\text { RSV } \\
\left(2^{\text {nd }}\right. \\
\text { scan })\end{array}$ & $\begin{array}{l}\text { Min-Max } \\
\text { RSV of the } \\
2^{\text {nd }} \text { scan }\end{array}$ & $\begin{array}{l}\text { Number of } \\
\text { operations }\end{array}$ \\
\hline $28-32$ & $\begin{array}{l}5.95 \\
(21-24)\end{array}$ & 9.24 & $1-10$ & 33 \\
$33-37$ & $\begin{array}{l}7.42 \\
(16-30)\end{array}$ & 8.69 & $2-10$ & 110 \\
$38-42$ & $\begin{array}{l}8.35 \\
(18-34)\end{array}$ & 8.31 & $4-10$ & 172 \\
$43-47$ & $\begin{array}{l}8.60 \\
(21-37)\end{array}$ & 8.45 & $2-10$ & 278 \\
$48-52$ & $\begin{array}{l}8.57 \\
(22-45)\end{array}$ & 9.15 & $5-10$ & 178 \\
$53-57$ & $\begin{array}{l}8.79 \\
(21-44)\end{array}$ & 9.46 & $7-10$ & 123 \\
$58-62$ & $\begin{array}{l}8.73 \\
(23-43)\end{array}$ & 9.29 & $6-10$ & 85 \\
$63-68^{*}$ & $\begin{array}{l}9.19 \\
(30-53)\end{array}$ & 9.60 & $8-10$ & 31 \\
\hline
\end{tabular}

Table 4. Mean day of the ultrasonography scan grouped according to the 1st given RSV

\begin{tabular}{llll}
\hline $\begin{array}{l}\text { 1st scan } \\
\text { RSV }\end{array}$ & $\begin{array}{l}\text { Mean day of } \\
\text { the 1st scan }\end{array}$ & $\begin{array}{l}\text { Mean RSV of } \\
\text { the 2nd scan }\end{array}$ & $\begin{array}{l}\text { Number of } \\
\text { operations }\end{array}$ \\
\hline $1-5.5$ & $24(18-42)$ & 7.98 & 67 \\
$6-6.5$ & $26(22-42)$ & 8.39 & 52 \\
$7-7.5$ & $28(16-44)$ & 8.70 & 111 \\
$8-8.5$ & $30(16-44)$ & 8.85 & 213 \\
$9-9.5$ & $31(16-47)$ & 8.91 & 332 \\
10 & $31(22-53)$ & 9.11 & 229 \\
\hline
\end{tabular}

Based on the images of Figure 1, taking into consideration the various pre-natal stages, the different images correspond to the differential stages. Particularly, images RSV 0,1 and 2, demonstrate the complete absence of pregnancy or the presence of a non viable morula, whereas a RSV 3 or 4 indicates the lowest suspicion for pregnancy, however with a definitely small litter size. The pregnancy is guaranteed not earlier than $\mathrm{RSV}=5$, where for the first time at least one healthy morula or blastocyst is depicted implying the ensured embryonic development. RSVs 6,7 and 8 similarly demonstrate the guaranteed pregnancy with a medium, possibly larger and satisfactory litter size, respectively. Finally, RSV 9 or 10 demonstrate the the emergence of the embryonic axis and the early organ development during the stage of neurula in combination with the greatest possible litter size. Keeping in mind that the first ultrasonography is performed approximately 25 days post insemination or mating, RSVs between 5 and 10 indicate the normal embryogenesis rates.

Based on Tables 3 and 4, the low RSVs occurred at second scan, correspond to a very low number of observations, whereas the mean value for the days derived from all categories remains high. The trend of the mean RSVs of the first operation seems to follow the values of the second scan in accordance with their categorization.

\section{DISCUSSION}

The sow is a polyestrous animal exhibiting estrus throughout the year, whereas their estrous cycle usually lasts 18-24 days with an average of 21 . The precise detection of estrus is of high importance for achieving high reproductive yields and the success of artificial insemination when applied [17]. The main symptoms of animals in estrus include the unusual behavior and mobility, decreased appetite, nervousness, swelling and redness of the vulva, mucus coming out of the vulva, the tendency to ride on other pigs and the reflex of immobility. Failure to accurately detect estrus may have a great impact on the birth rate and the size of the delivery group [18]. The estrous cycle is interrupted during pregnancy and sow milk production. Thus, the early and accurate diagnosis of pregnancy improves reproductive capacity on commercial pig farms.

In the present work we studied the ultrasonic typification of sows in an effort to develop a methodology for the precise pregnancy diagnosis and the prediction of the number of born piglets. According to the detailed observation of the ultrasonic image of the sow, a rating scale was established based on the number of the embryonic vesicles and the degree of filling of the ultrasonic image.

Taking into consideration the reproduction data of the animals tested, namely the high fecundity $(86.18 \%)$, the birth rate $(83.20 \%)$ and the mean number of born piglets (12.22), the pig unit from which we obtained the data can be characterized as a high-yield commercial farm. Specifically, the fecundity data are within the range of typical commercial farms according to the review of Stalder et al. [19], whereas the numbers of born piglets are similar with other pig farms in Europe [20].

The given scores of the developed rating scale of the ultrasonic image were almost always high for the sows that gave birth, lower for the sows that aborted and very low for the ones that returned to estrus. This fact can be probably attributed to the density of the fluid within the uterus that is greater in pregnant than in non-pregnant sows [21]. Regarding the precise time post insemination, the day of the operation showed a statistically significant effect on the given score. In particular, after day 26 post insemination the given scores were stabilized in high levels, while earlier estimations between days 21-26 were lower ranging from 6 to 7. These results agree and extend previous studies concluding that pregnancy can be easily diagnosed in sows after day 16 post mating or artificial insemination due to the accumulation of fluid in the uterus [13] and more specifically that between days 23 and 30 the diagnosis has the highest success rates [22]. It is generally proven that after day 28 post mating or 
insemination, ultrasonography provides diagnosis results with high accuracy, which is even higher when the operation takes place twice [11]. In line with these inferences, the diameter of the embryonic vesicles increases up to day 30 and then starts to decrease [23]. On the other hand, the low scores obtained between days 21 and 25 are probably owing to the fetal growth, which occupies the largest proportion of the ultrasonic image [24]. The lower scale scores observed in sows that were pregnant and aborted, probably indicate a bad fetal health, which is also reflected in ultrasonography.

The rating scale scores indicated also a significant effect on the total number of born piglets. Although the day of the operation does not affect significantly this number, the prediction model was improved taking into account the day as a covariance factor. The rating scale scores showed a higher effect on the total number of born piglets when the impact of the sow was taken into account. This could be due to various features such as genetic characteristics of the sow, management of the sow in the first life stages, parity number, duration of the lactation and the quality of the semen $[25,26]$. Thus, it has to be noted that the prediction model is not of high accuracy. However, there is a great potential of improvement in predicting the number of piglets and a general principle that not clear and uncertain image is usually an indication of small litter size [14,27-28]. The prediction of litter size based on the ultrasonic image is a very promising perspective of the ultrasonography technology that can work as a tool of high importance in pig farming. In general, using a numerical software for the early detection of numerous biological parameters is a very powerful tool for their proper diagnosis and their management [29,30]

In conclusion, the developed rating scale provides reliable and accurate pregnancy diagnosis between day 25 and 35 post mating or artificial insemination. Although the given scores are stable and high in pregnancy diagnosis after day 35 , there is the drawback of not accurately predicting the litter size on this time point. In this context, the second scan is of lower zootechnical value. Thus, future research should be more focused on the precise diagnosis of litter size, the earliest possible, which is of high economic value for the management of the farm [31]. Nevertheless, it should be pointed out that the litter size prediction model is generic and works properly under the condition that there is a correction regarding the duration in days between the mating and the operation. The developed scale could be the basis for the utilization of ultrasonography under the framework of precision pig farming, for the detailed examination and automatic connection to a management software of pregnant sows. Incorporating also additional data, future analyses will be directed towards the integration of various factors such as the parity profile, the age and the weight of the sow, the age of first mating and the features of the male.

\section{References}

[1] Sørensen, J.T.; Edwards, S.; Noordhuizen, J.; Gunnarsson, S. Animal production systems in the industrialized world. Rev. Sci. Off. Tech. Int. Epiz. 2006, 25, 493-503.

[2] McGlone, J.J. The future of pork production in the world: Towards sustainable, welfare-positive systems. Animals 2013, 3, 401-415. http://doi.org/10.3390/ani3020401

[3] Flowers, W.L. Applying reproductive technologies in practice. Proceedings of the London Swine Conference-Facing the New Reality, 2008, 185-194.

[4] Kim, S.W.; Weaver, A.C.; Shen, Y.B.; Zhao, Y. Improving efficiency of sow productivity: nutrition and health. Journal of animal science and biotechnology, 2013, 4(1), 26.

[5] Rhodes, R.T.; Appleby, M.C.; Chinn, K.; Douglas, L.; Firkins, L.D.; Houpt, K.A.; Irwin, C.; McGlone, J.J.; Tokach, L.; Wills, R.W. A comprehensive review of housing for pregnant sows. J. Am. Vet. Med. A. 2005 227, 1580-1590. http://doi.org/10.2460/javma.2005.227.1580

[6] Cunha, E.C.P.; de Alcantara Menezes, T.; Bernardi, M.L.; Mellagi, A.P.G.; da Rosa Ulguim, R.; Wentz, I.; Bortolozzo, F.P. Reproductive performance, offspring characteristics, and injury scores according to the housing system of gestating gilts. Livest. Sci. 2018, 210, 59-67. http://doi.org/10.1016/j.livsci.2018.02.008

[7] Shen, J.; Zhou, C.; Zhu, S.; Shi, W.; Hu, M.; Fu, X.; Yu, Y. Comparative transcriptome analysis reveals early pregnancy-specific genes expressed in peripheral blood of pregnant sows. PloS one, 2014, 9(12), e114036.

[8] Lents, C.A.; Cushman, R.A.; Freking, B.A. Measures of the ovaries and uterus during development of gilts selected for differences in uterine capacity. J. Anim. Sci. 2014, 92, 2433-2439.

[9] Stančić, I.; Beuković, M.; Dragin, S.; Erdeljan, M.; Apić, I. Pregnancy Diagnosis by Real-Time Ultrasonograpy at Different Gestational Periods in Gilts and Sows. Scientific Papers Animal Science and Biotechnologies, 2012, 45(2), 404407.

[10] Kauffold, J.; Althouse, G.; Beynon, N. Ultrasound scanning - more than just pregnancy testing. Western Hog Journal, summer. 2011

[11] Williams, S.I.; Piñeyro, P.; de la Sota, R.L. Accuracy of pregnancy diagnosis in swine by ultrasonography. Canada Vet. J. 2008, 49, 269.

[12] Kahn, W. Veterinary Reproductive Ultrasonography. Schlutersche Verlagsgesellschaft $\mathrm{mbH} \& \mathrm{Co}$, Hannover. 2004

[13] Knox, R.V.; Althouse, G.C. Visualizing the reproductive tract of the female pig usingreal-time ultrasonography. J. Swine Health Prod. 1999, 7, 207-215.

[14] Knox, R.; Flowers, W. Using real-time ultrasound for pregnancy diagnosis in swine. Pork Information Gateway, Factsheet PIG 08-04-01. 2001.

[15] Kauffold, J.; Althouse, G.C. An update on the use of Bmode ultrasonography in female pig reproduction. Theriogenology 2007, 67, 901-911. 
[16] Martinat-Botté, F.; Renaud, G.; Madec, F.; Costiou, P.; Terqui, M. Ultrasonography and Reproduction in Swine: Principles and Practical Applications. INRA, Paris, 2000

[17] Estienne M.J.; Harper A.F. Using Artificial Insemination in Swine Production: Detecting and Synchronizing Estrus and Using Proper Insemination Technique. Virginia Cooperative $\quad$ Extension. 2009. http://pubs.ext.vt.edu/414/414-038/414-038.html

[18] Kraeling R.R.; Webel S.K. Current strategies for reproductive management of gilts and sows in North America. I Anim Sci Biotechnol. 2005 31;6:3. DOI: 10.1186/2049-1891-6-3

[19] Stalder, K.J.; Knauer, M.; Baas, T.J.; Rothschild, M.F.; Mabry, J.W. Sow longevity. Pig News and information 2004, 25, 53-74.

[20] Rutherford, K.M.D.; Baxter, E.M.; D'Eath, R.B.; Turner, S.P.; Arnott, G.; Roehe, R.; Ask, B.; Edwards, S.A.; Berg, P.; Lawrence, A.B. The welfare implications of large litter size in the domestic pig I: biological factors. Anim Welf, 2013, 22, 199-218.

[21] Flowers, W.L.; Knox, R.V. Pregnancy diagnosis in swine, in: Singleton, W. (Eds.), Pork Industry Handbook Vol 2. 2010. Purdue University Press, West Lafayette, USA, pp. 47-57.

[22] Szenci, O.; Fekete, C.; Merics, I. Early pregnancy diagnosis with a battery-operated ultrasonic scanner in sows. Canada Vet. J., 1992, 33, 340.

[23] Miller, D.L.; Smith, N.B.; Bailey, M.R.; Czarnota, G.J.; Hynynen, K.; Makin, I.R.S. Overview of therapeutic ultrasound applications and safety considerations. J. Ultrasound Med. 2012, 31, 623-634.

[24] Lepercq, M.; Martinat-Botte, F.; Forgerit, Y.; Terqui, M. Use of ultrasound echography to study embryonic development in the sow. Ann. Zootech. 1987, 36, 304.

[25] Lawlor, P.G.; Lynch, P.B. A review of factors influencing litter size in Irish sows. Ir. Vet. J. 2007, 60, 359.

[26] Wolf, J. Heritabilities and genetic correlations for litter size and semen traits in Czech Large White and Landrace pigs. J. Anim. Sci. 2010, 88, 2893-2903.

[27] Taverne, M.A.M.; Oving, L.; Van Lieshout, M.; Willemse, A.H. Pregnancy diagnosis in pigs: A field study comparing linear-array real-time ultrasound scanning and amplitude depth analysis. Vet. Q. 1985, 7, 271-276.

[28] Maes, D.; Nauwynck, H.; Rijsselaere, T.; Mateusen, B.; Vyt, P.; de Kruif, A.; Van Soom, A. Diseases in swine transmitted by artificial insemination: an overview. Theriogenology 2008, 70, 1337-1345.

[29] Deepa, T.P.; Jhanhavi; Ramya, S.; Pavithra; Kumar S. Counting cells in microscopic image using two-phase segmentation. WSEAS Transactions on Signal Processing 2018, 14, 8-14.

[30] Maji, P.; Mandal, A.; Ganguly, M.; Saha, S. An automated method for counting and characterizing red blood cells using mathematical morphology. In 2015 Eighth International Conference on Advances in Pattern Recognition (ICAPR) (pp. 1-6). IEEE.
[31]Berckmans, D. Precision livestock technologies for welfare management in livestock systems. Scientific and technical review of the Office International des Epizooties, 2014, 33(1), 189-196.

\section{Creative Commons Attribution License 4.0 (Attribution 4.0 International, CC BY 4.0)}

This article is published under the terms of the Creative Commons Attribution License 4.0 https://creativecommons.org/licenses/by/4.0/deed.en_US 